\title{
Adaptive Policy Design to Reduce Carbon Emissions: A System-of-Systems Perspective
}

\author{
Datu Buyung Agusdinata and Lars Dittmar
}

\begin{abstract}
This paper presents an adaptive policy design approach based on a system-of-systems (SoS) perspective. Using a case of carbon emissions reduction in the residential sector, the SoS perspective is used as a way to structure the policy issue into interdependent relevant systems. This representation of the system provides a framework to test a large number of hypotheses about the evolution of the system's performance using computational experiments. In particular, in a situation where the realized emission level misses the intermediate target, policies can be adapted to meet the policy target. Our approach shows the different policy designs that decision-makers can envision to influence the overall system performance.
\end{abstract}

Index Terms-Adaptive policy design, carbon emission reduction, household emissions, system-of-systems.

\section{INTRODUCTION}

I $\mathrm{N}$ application areas such as environmental and energy systems, the increasingly complex and uncertain nature of the problems under study can pose significant methodological challenges for research. To address such challenges, a systems-level approach is urgently needed [1]. Two major shifts are from system to system-of-systems thinking and from optimal to adaptive.

In support of these challenges, a number of approaches have been developed and tested with mixed success. In dealing with complexity, professionals from the various domains are typically trained to solve problems using methods and ideas of relevance to their own domain. The engineering design paradigm is one such example. This legacy is the source of the often-used term 'stovepipe' in reference to narrow scope thinking in a particular area of specialty. The real dynamics of climate change issues, for example, can only be fully understood 'across' stovepipes, spanning various domains of knowledge. A holistic frame of reference is required for such trans-domain applications. We argue in this paper that a system-of-systems (SoS) perspective provides such a frame of reference.

Manuscript received June 16, 2009; revised September 14, 2009. First published November 03, 2009; current version published January 27, 2010. This work was supported by The Next Generation Infrastructure Foundation and by the Dutch Organization for Scientific Research (NWO) under the research program "Managing uncertainties in energy innovations and transition processes".

D. B. Agusdinata was with the Faculty of Technology, Policy, and Management, Delft University of Technology, Delft, The Netherlands. He is now with the System-of-Systems Laboratory, Purdue University, West Lafayette, IN, 47907 USA (e-mail: bagusdin@purdue.edu).

L. Dittmar is with the Copernicus Institute-Department of Science, Technology, and Society, Utrecht University, Utrecht, The Netherlands (e-mail: 1.dittmar@chem.uu.nl).

Digital Object Identifier 10.1109/JSYST.2009.2032992
In dealing with uncertainty, most analyses supporting the design of policy for carbon emissions reductions are still based on a "predict-then-act approach" [2]. This approach may result in an optimum policy that is based on best estimates of the states of the system and future external developments or scenarios. Even worse, this approach may lead to inaction when it is felt that the uncertainties are too large to warrant any policy efforts [3]. This predict-then-act approach has been successful when there is sufficient knowledge and information about the system of interest, usually in the form of probability distributions of the relevant variables. But under conditions of deep uncertainty, it carries the risk of significant prediction errors, which may lead the chosen policy to fail.

This paper presents a SoS-oriented approach that addresses complexity and uncertainty in policymaking. The approach is described first, followed by a description of its application to a case in the Dutch residential sector. The application illustrates how the approach supports an adaptive policy design. The paper concludes with implications for policy design.

\section{TECHNICAL APPROACH}

\section{A. SoS Perspective}

SoS Lexicon: To be able to provide a basis for the abstraction and conceptualization of SoS for policymaking purposes, a lexicon has been developed. DeLaurentis and Callaway [4] define a lexicon in terms of levels and categories, as shown in Table I. The categories highlight the presence of a heterogeneous mix of engineered and human systems that together constitute the dimensions of the problem. For each category, there is a hierarchy of components. To avoid confusion, the lexicon employs unambiguous Greek symbols to establish the hierarchy. Alpha $(\alpha)$, Beta $(\beta)$, Gamma $(\gamma)$, and Delta $(\delta)$ indicate the relative positions within each category. The collection of $\alpha$ entities and their connectivity determines the construct of a $\beta$-level network and likewise, a $\gamma$-level network is an organized set of $\beta$ networks. Hence, the $\delta$-level can be described as a network comprised of all of the lower level networks, whose constituents span the category dimensions.

Through the use of the lexicon in understanding multilevel relationships, decisions of one stakeholder may be appropriately tailored in the context of the actions of others.

Actors and Artifacts: The above lexicon is operationalized and tailored for policymaking purposes [5]. A SoS is considered to constitute a network of actors and artifacts.

Fig. 1 depicts our definition of an actor and an artifact in a SoS. Depending on the specific context at hand, an actor oversees a system of interest that comprises certain system state variables $(S)$. The actor can exert direct control using levers $(L)$ to 
TABLE I

SOS LEXICON

\begin{tabular}{|c|c|}
\hline Category & Description \\
\hline Resources & $\begin{array}{l}\text { The entities (systems) that give physical } \\
\text { manifestation to the system-of-systems }\end{array}$ \\
\hline Stakeholders & $\begin{array}{l}\text { The individual/organizational entities that give } \\
\text { intent to the SoS through values }\end{array}$ \\
\hline Organizations & $\begin{array}{l}\text { The institutional configuration and process that } \\
\text { guide the interactions among stakeholders }\end{array}$ \\
\hline Operations & $\begin{array}{l}\text { The application of intent to direct the activity of } \\
\text { entity networks }\end{array}$ \\
\hline $\begin{array}{l}\text { Economics/ } \\
\text { Financial }\end{array}$ & $\begin{array}{l}\text { The monetary considerations that drive the operation } \\
\text { of entity networks }\end{array}$ \\
\hline Policies & $\begin{array}{l}\text { The functions that guide the operation of resource } \\
\text { and stakeholder entities }\end{array}$ \\
\hline Level & Description \\
\hline Alpha $(\boldsymbol{\alpha})$ & $\begin{array}{l}\text { Base level of entities in each category, further } \\
\text { decomposition will not take place }\end{array}$ \\
\hline Beta $(\boldsymbol{\beta})$ & $\begin{array}{l}\text { Collections of } \boldsymbol{\alpha} \text {-level systems (across categories), } \\
\text { organized in a network }\end{array}$ \\
\hline $\operatorname{Gamma}(\boldsymbol{\gamma})$ & $\begin{array}{l}\text { Collections of } \boldsymbol{\beta} \text {-level systems (across categories), } \\
\text { organized in a network }\end{array}$ \\
\hline Delta $(\boldsymbol{\delta})$ & $\begin{array}{l}\text { Collections of } \boldsymbol{\gamma} \text {-level systems (across categories), } \\
\text { organized in a network }\end{array}$ \\
\hline
\end{tabular}

affect the outcomes of interests $(O)$, which are also dependent on factors that are beyond the influence of the operator (exogenous factors, $X$ ). The interactions among all these elements are governed by relationships $(R)$; that is

$$
O=R(X, S, L) .
$$

The relationships $R$ can be functional, correlational, and/or behavioral. Subject to uncertainties regarding the exogenous factors $(X)$, the actor will make decision $L^{*}$ that satisfies his value system $\mathrm{V}$, which is a function of his goals, interests, and preferences, hence

$$
L^{*}=\operatorname{Max}_{v}(O) .
$$

An artifact, by contrast, only features a system that receives inputs (i.e., exogenous factors, $X$ ) and produces outputs (i.e., outcomes of interests, $O$ ). An artifact cannot act on its own and is acted upon by actors. An intelligent nonhuman system (such as a programmed robot) should be considered an actor rather than an artifact.

A Synthesis of the constructs above is a network of interdependence systems across various levels (see Fig. 2).

\section{B. Adaptive Policy Approach}

In contrast to the predict-then-act optimal approach, the adaptive approach can be characterized in several ways [8]. First, it does not require that all uncertainties be resolved before a policy can be designed and implemented. Second, it also makes explicit the aspect of learning in resolving the uncertainties. Third,

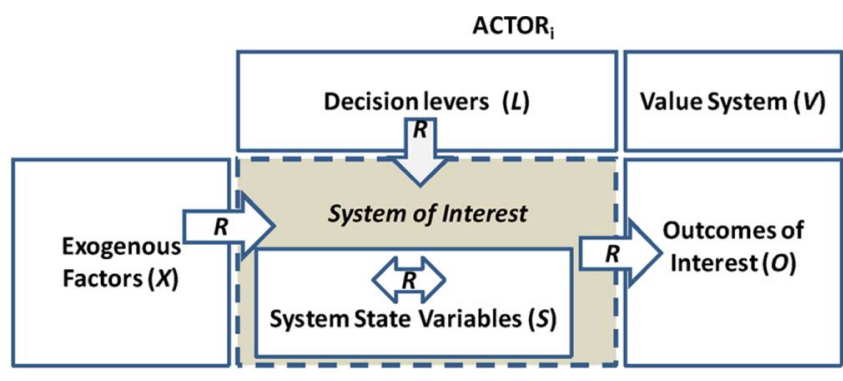

(a)

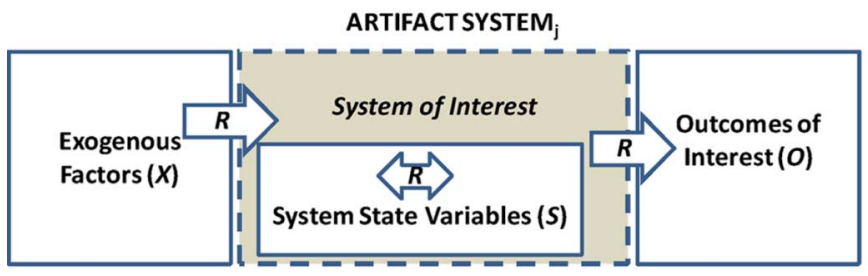

(b)

Source: adapted from [5-7]

Fig. 1. Definition of (a) actor and (b) artifact in a SoS.

it uses a monitoring system that triggers calls for policy adaptations. It has been demonstrated, for example, that adaptive policymaking can correct and therefore avoid costs as a result of the failure of an optimal policy [9].

\section{Exploratory Modeling (EM)}

To support the design of an adaptive policy, we use the EM method. EM involves exploring as broad a range of assumptions and circumstances as are plausible given the resources available for the analysis [10]. Exploratory modeling involves examining a wide variety of scenarios, alternative model structures, states of the system, and value systems. The exploration is carried out using computational experiments. A single computational experiment is a computer run for one set of assumptions (a plausible hypothesis) regarding the external scenario, the system model, and the value system. Exploratory modeling is applied to "cover the space" of possibilities, namely the space created by the uncertainty surrounding the many variables. Whether a computational experiment is valid depends on whether the space has been properly conceived and sampled, and the results interpreted properly [11].

We now illustrate the application of our approach to policy measures to reduce carbon emissions in the Dutch residential sector.

\section{Case Study: The Dutch Residential EMissions}

The Dutch Government aims to reduce carbon emissions by $60-80 \%$ in 2050 compared to 1990 levels [12]. Residential energy use accounted for $17 \%$ of the national final energy consumption in the year 2000 and $11 \%$ to the total energy related $\mathrm{CO}_{2}$ emissions of the Netherlands [13]. Since $97 \%$ of all households are connected to the natural gas grid, residential space and water heating demand is met almost exclusively by natural gas.

Ever since the first oil crises of 1973, the residential sector has been the subject of a vast number of energy conservation efforts and, more recently, carbon restraint policies [14]. In spite 


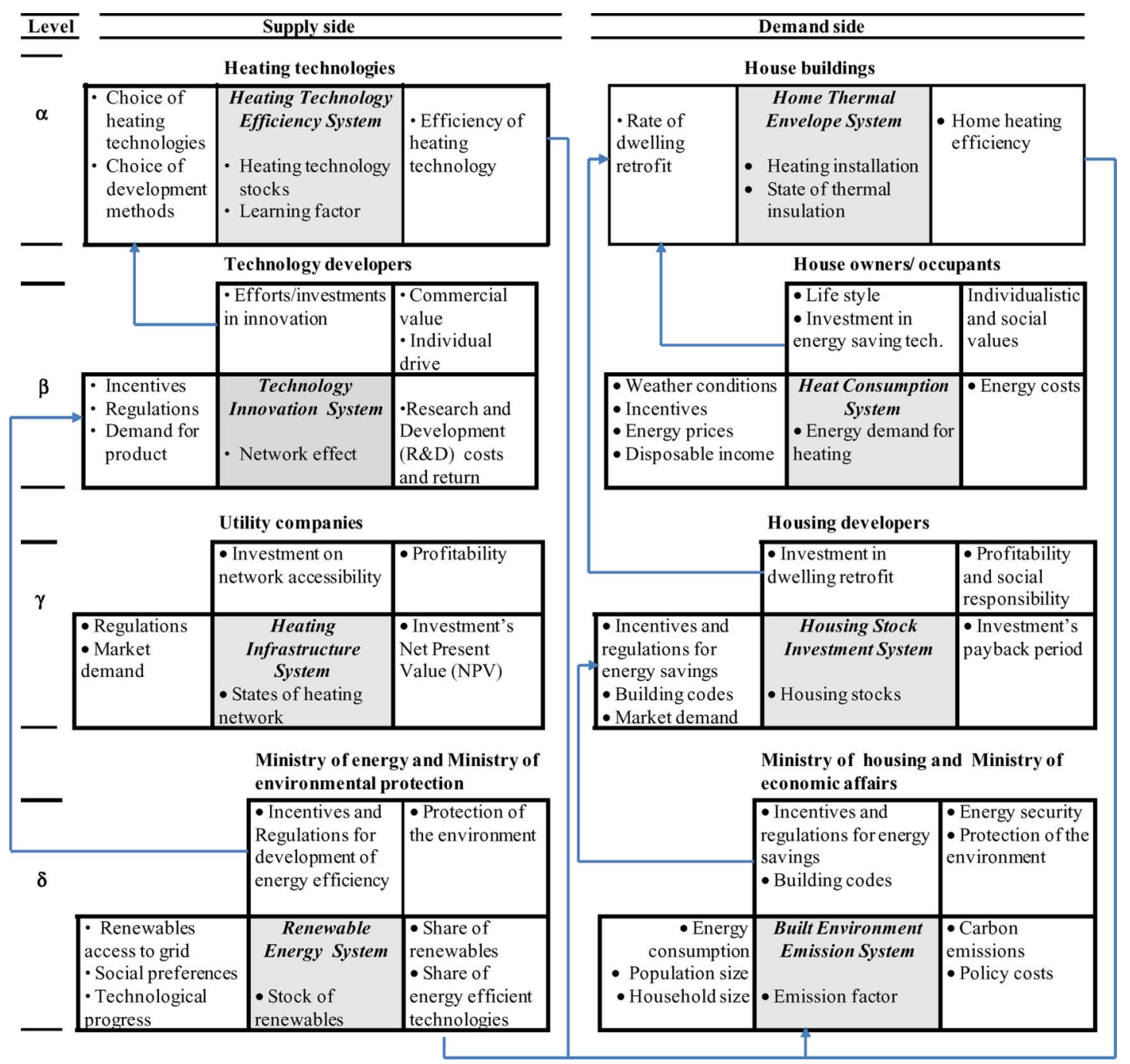

Fig. 2. Specification of SoS for policymaking to reduce carbon emissions in the residential sector.

of these efforts, various studies indicate that the potential for energy efficiency improvements within the built environmental is still enormous, especially in the existing building stock [15], [16]. One policy that has been implemented involves subsidy schemes for energy-saving refurbishments of existing homes.

\section{SoS SPECIFICATION FOR THE RESIDENTIAL SECTOR}

For each SoS level (denoted by Greek symbols) and from both the supply and demand side, the relevant systems and actors are specified (see Fig. 2). External forces $(X)$ and decision levers $(L)$ act upon the system, whose structure is defined by its system state variables $(S)$ and relationships $(R)$. The interactions among such factors result in the outcome of interest $(O)$, whose desirability is determined by the decision-makers' value system $(V)$. This specification is based on the work of Agusdinata and DeLaurentis [17].

For the supply and demand side, each system across the SoS levels is briefly described as follows:

$\alpha$ Level: On the supply side, the system is the heating technology efficiency system (i.e., an artifact) that describes the state of heating technology stocks, whose outcome of interest is primarily the efficiency of the heating technologies. On the demand side, the system is the home's thermal envelope system, which comprises the state of heating installations and thermal insulation.

$\beta$ Level: On the supply side, the system is the heating technology innovation system that describes private and public technology developers' attempts to produce more efficient heating technology at affordable cost. On the demand side, we can define a heat consumption system in which house occupants decide how to consume energy for heating, consistent with their lifestyles. The energy consumption, which results in energy costs for occupants, also depends on weather conditions, energy prices, and disposable income.

$\gamma$ Level: On the supply side is the heating infrastructure system, in which utility companies invest in infrastructure. On the demand side is the housing stock investment system, in which housing developers and home owners invest in the state of the housing stocks. For both systems, investment decisions are based on profitability criteria (e.g., Net Present Value, NPV, and payback periods). Investment decisions regarding 
energy/cost-saving technology are based on various factors such as energy prices and incentives (e.g., subsidies).

$\delta$ Level: On the supply side is the renewable energy system for which policies are designed to influence the penetration of renewables in the energy supply chain. On the demand side is the built-environment emission system in which the main concern is the level of $\mathrm{CO}_{2}$ emissions and the associated cost to achieve the policy goal of reducing the emissions levels. Both systems feature the Dutch government, divided into several respective ministries, playing the role of controlling actor. To influence the performance of the SoS, they use policy instruments such as subsidies and regulation of building codes.

From the SoS perspective, each level requires a unique set of policies and there exist interdependencies among the systems, both across and between levels. For example, the technology innovation system, at the $\beta$ level, depends on the regulatory and financial support that comes from the decision-makers (i.e., actor) at the $\delta$ level. Another example is how the emissions factor (i.e., the $S$ in the built environment emission system) is influenced by other factors in the SoS. This factor accounts for the emissions that are generated for each unit of energy produced. The emissions factor is influenced by: i) the efficiency of heating technologies ( $O$ at the $\alpha$ level); ii) building thermal efficiency ( $O$ at the $\alpha$ level); and iii) the share of renewables in the heating energy supply chain ( $O$ at the $\delta$ level). So, from a SoS perspective, policies and decisions can join towards a concerted effort to influence the overall system performance (i.e., carbon emissions levels).

\section{A. Computer Model}

For our computational experiments, we made use of the Dutch Residential Energy Model (DREM) [18]. DREM simulates the evolution of the Dutch housing stock from 2000 to 2050, focusing on energy consumption, $\mathrm{CO}_{2}$ emissions, and technology dynamics. Based on 26 representative homes, the model simulates changes over time through retirements, new construction, refurbishment of existing homes, and initial as well as replacement purchases of heatingequipment.

The aforementioned SoS framework is reflected within the model structure through functional relationships and system variables. The specification of the uncertainty space to be explored is represented by a range of system variables (see Table II). The range implies uniform distributions.

$\alpha$ Level: On the supply side, technological devolvement is modeled by the well-known concept of technological experience curves [19], [20], describing cost reductions of technologies as a function of accumulated experience in the form of units installed

$$
\operatorname{Inv}(k, t)=I_{0}(k) \cdot \mathrm{CU}\left(k, t_{-1}\right)^{-L R}
$$

where $I_{0}$ are the initial investment costs, CU are cumulative installed units, and $L R$ is the learning rate. Uncertainties are expressed through a range of $L R s$. Large values of $L R$ indicate a steep curve with a high learning rate. Technologies considered for learning curves are solar thermal systems, electric driven heat pumps, gas driven heat pumps, and micro- combined heat and power (CHP) applications.
TABLE II

System VARIables AND THEIR Plausible Ranges

\begin{tabular}{|c|c|c|c|}
\hline Level & System Variable & $\begin{array}{l}\text { Description and } \\
\text { symbol }\end{array}$ & Range \\
\hline$\alpha$ & $\begin{array}{l}\text { Learning rates for } \\
\text { four technologies }\end{array}$ & $\begin{array}{l}\text { LR1: electricity - } \\
\text { driven heat pump } \\
L R 2: \text { solar thermal } \\
\text { heating systems } \\
\text { LR3: micro-CHP } \\
\text { LR4: gas-driven heat } \\
\text { pumps }\end{array}$ & {$[10 \%, 20 \%]$} \\
\hline \multirow{4}{*}{$\beta$} & $\begin{array}{l}\text { Annual growth in } \\
\text { gas price }\end{array}$ & $\begin{array}{l}G 1(2000-2025) \\
G 2(2025-2050)\end{array}$ & $\begin{array}{l}{[2 \%, 4 \%]} \\
{[2 \%, 6 \%]}\end{array}$ \\
\hline & $\begin{array}{l}\text { Annual growth in } \\
\text { electricity price }\end{array}$ & $\begin{array}{l}\text { E1 (2000-2025) } \\
\text { E2 (2025-2050) }\end{array}$ & $\begin{array}{l}{[1 \%, 3 \%]} \\
{[1 \%, 5 \%]}\end{array}$ \\
\hline & Discount rate & $D R$ & {$[5 \%, 20 \%]$} \\
\hline & $\begin{array}{l}\text { Parameter lambda } \\
\text { technology }\end{array}$ & $L T$ & {$[2,12]$} \\
\hline \multirow{3}{*}{$\gamma$} & Demolition rate & RET & {$[0,4]$} \\
\hline & $\begin{array}{l}\text { Acceptable } \\
\text { payback }\end{array}$ & $P B$ & {$[5,10]$ years } \\
\hline & $\begin{array}{l}\text { Parameter lambda } \\
\text { refurbishment }\end{array}$ & $L F$ & {$[2,6]$} \\
\hline \multirow{5}{*}{$\delta$} & \multirow{2}{*}{ Subsidy level } & SUB1 (2000-2025) & $20 € /$ ton $\mathrm{CO}_{2}$ \\
\hline & & SUB2 (2025-2050) & $\begin{array}{l}20,50, \text { and } \\
70 € / \text { ton } \mathrm{CO}_{2}\end{array}$ \\
\hline & Building code & CODE & {$[2.5 \%, 5 \%]$} \\
\hline & $\begin{array}{l}\text { Growth rate of } \\
\text { household size }\end{array}$ & $H Z$ & $\begin{array}{l}{[-0.4 \%,-} \\
0.2 \%]\end{array}$ \\
\hline & $\begin{array}{l}\text { Rate of } \\
\text { population } \\
\text { growth }\end{array}$ & $P O P$ & $\begin{array}{l}{[-0.5 \%,} \\
0.5 \%]\end{array}$ \\
\hline
\end{tabular}

$\beta$ Level: Market shares of competing heating technologies are simulated by a logit market sharing function [21], [22], which assumes that energy users face a set of heating technologies that follow a Weibull cost distribution with a shape parameter $(L T)$, common to all technologies. The market share of a technology is equal to the probability that this technology is of lower cost than any of the competing options. The closed form of the logit sharing function is given by

$$
\operatorname{MS}\left(k^{\prime}\right)=\frac{\bar{c}\left(k^{\prime}\right)^{-L T}}{\sum_{k}^{n} \bar{c}(k)^{-L T}}
$$

where $\operatorname{MS}\left(k^{\prime}\right)$ is the market share of technology $k^{\prime}, \bar{c}(k)$ are the "intrinsic costs" [22] of the kth technology, and $L T$ is the Weibull shape parameter. The Weibull shape parameter measures the variance in the market. A low $L T$ implies that technology market shares are distributed relatively uniformly among all competing technologies, even if their costs differ significantly. For high values of $L T$, by contrast, the lowest cost technologies gain $100 \%$ market share with the smallest of cost differentials (see Fig. 3).

The logit function allocates market shares based on the annual cost equivalents of energy supply, which include annualized in- 


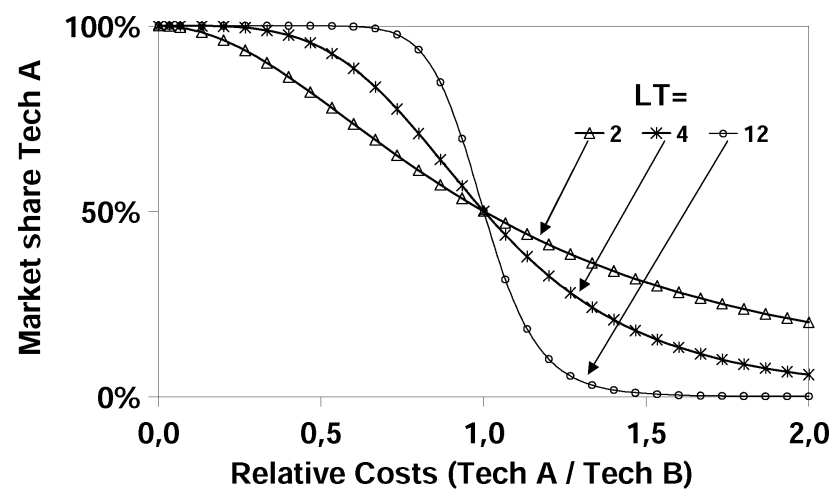

Fig. 3. Market share function based on $L T$.

TABLE III

U-VALUES FOR VARIOUS REFURBISHMENT OPTIONS

\begin{tabular}{|c|c|c|c|c|c|}
\hline & & \multicolumn{4}{|c|}{ Standard $(s t)$} \\
\hline \multicolumn{2}{|c|}{ Component (i) } & 1 & 2 & 3 & 4 \\
\hline \multirow{2}{*}{ Windows } & $W$ & \multirow{2}{*}{2.0} & \multirow{2}{*}{1.60} & \multirow{2}{*}{1.20} & \multirow[b]{2}{*}{0.70} \\
\hline & $\overline{m^{2} \cdot K}$ & & & & \\
\hline \multirow{2}{*}{ Walls } & $W$ & \multirow{2}{*}{0.77} & \multirow{2}{*}{0.4} & \multirow{2}{*}{0.33} & \multirow{2}{*}{0.25} \\
\hline & $\overline{m^{2} \cdot K}$ & & & & \\
\hline \multirow{2}{*}{ Roof } & $W$ & \multirow{2}{*}{0.40} & \multirow{2}{*}{0.33} & \multirow{2}{*}{0.25} & \multirow{2}{*}{0.20} \\
\hline & $\overline{m^{2} \cdot K}$ & & & & \\
\hline \multirow{2}{*}{ Floor } & $W$ & \multirow{2}{*}{0.50} & \multirow{2}{*}{0.40} & \multirow{2}{*}{0.33} & \multirow{2}{*}{0.25} \\
\hline & $\overline{m^{2} \cdot K}$ & & & & \\
\hline
\end{tabular}

vestment costs, operation and maintenance costs, fuel costs for space heating and domestic hot water, and, finally, the benefits from cogeneration technologies in the form of a reduced need to purchase electricity and the opportunity to sell surplus electricity. We consider the time preference of capital investment in the form of the discount rate $(D R)$, which is used to annualize all investment costs. A value range of 5\%-20\% is chosen to represent the discount rate. This range is designed to capture the high 'implicit' discount rates (or real hurdle rates), shown in consumer energy-efficiency investments, which are higher than conventional discount rates [23].

Energy price uncertainties are captured in terms of annual price growth multipliers ( $G$ for natural gas and $E$ for electricity), over two periods: 2000-2025 and 2025-2050. The changes in energy prices are modeled by a compound annual growth rate.

$\gamma$ Level: We model four energy efficiency refurbishments, namely improved thermal performances of roof, walls, floor and glazing. For each dwelling component, four competing performance standards of the respective dwelling home are defined in terms of their u-values (see Table III). The u-value is a measure of the rate of heat loss through a component, such that the lower the u-value is, the lower the heat loss will be.

In DREM, both the rate of refurbishment in each period and the market share of different insulation standards are modeled endogenously. While a payback acceptance curve (PAC) is used to simulate the rate of refurbishment, market shares for insulation standards are obtained by a logit function. The PAC describes the percentage of consumers who would adopt a refur- bishment standard if it yielded an acceptable critical payback. The simple payback time is given by

$$
P B(i, \mathrm{st})=\frac{\Delta I(i, \mathrm{st})}{\Delta E(i, \mathrm{st}) \cdot P_{e}}
$$

where $P B(i, \mathrm{st})=$ simple payback time of refurbishment standard $s t$ for dwelling component $i, \Delta I=$ additional investment costs related to the refurbishment standard $s t, \Delta E=$ resulting energy savings, and $P_{e}=$ energy price.

The logit function allocates market share based on the comparison of the paybacks, implying that the market share of a particular refurbishment standard is equal to the probability that this standard yields lower payback than any of the competing options

$$
\mathrm{MS}\left(\mathrm{st}^{\prime}\right)=\frac{P B\left(\mathrm{st}^{\prime}\right)^{-L F}}{\sum_{\mathrm{st}}^{n} P B(\mathrm{st})^{-L F}}
$$

where $\mathrm{MS}\left(\mathrm{st}^{\prime}\right)$ is the market share of standard $\mathrm{st}^{\prime}, P B(\mathrm{st})$ is the "intrinsic payback" of the standard st, and $L F$ is the Weibull shape parameter. The interpretation of the shape parameter, $L F$, is analogous to the shape parameter $L T$ in (4). For high values of $L F$, the standards with lowest payback gain the greatest market share, while for low values of $L F$ the market shares are relatively evenly distributed.

We use the mean of the minimum payback distribution, obtained from the logit, and estimate these using the rate of refurbishment in a PAC. The mean of the minimum payback distribution is given as [21], [22]

$$
P B_{\mathrm{AV}}(i)=\left[\sum_{\mathrm{st}} P B(i, \mathrm{st})^{-L F}\right]^{-\frac{1}{L F}}
$$

where $P B_{\mathrm{AV}}$ is the mean payback of component $i$ across standard $s t, P B$ is the intrinsic payback of the standard $s t$, and $L F$ is the Weibull distribution's shape parameter.

The PAC is assumed to be a standard logistic function

$$
\operatorname{RR}(i)=\operatorname{RR}_{\max }(i) \cdot\left\{1-\frac{1}{1+e^{\left(-\left(P B_{\mathrm{AV}}(i)-P B\right)\right)}}\right\}
$$

where $\mathrm{RR}=$ rate of refurbishment of dwelling component $i, \mathrm{RR}_{\max }=$ technical refurbishment potential of component $i, P B_{\mathrm{AV}}=$ minimum mean payback, and $P B=$ acceptable payback. For each component, the rate of refurbishment represents the technical potential multiplied by the percentage of customers who would accept the payback. The PAC is defined such that in $50 \%$ of all cases refurbishment will be undertaken, subject to the condition that the payback period equals the acceptable value $(P B)$ (see Fig. 4).

Finally, uncertainty about the rate of housing demolition (RET) is explored using four empirically established survival functions of Dutch housing stock, describing the demolition of homes as a function of their age [24]-[26]. These survival functions differ in the rate of demolition: for $R E T=0$ the demolition rate is the highest and for $R E T=4$ the lowest.

$\delta$ Level: We test a subsidy arrangement to stimulate energy efficiency refurbishments in households. This subsidy directly 


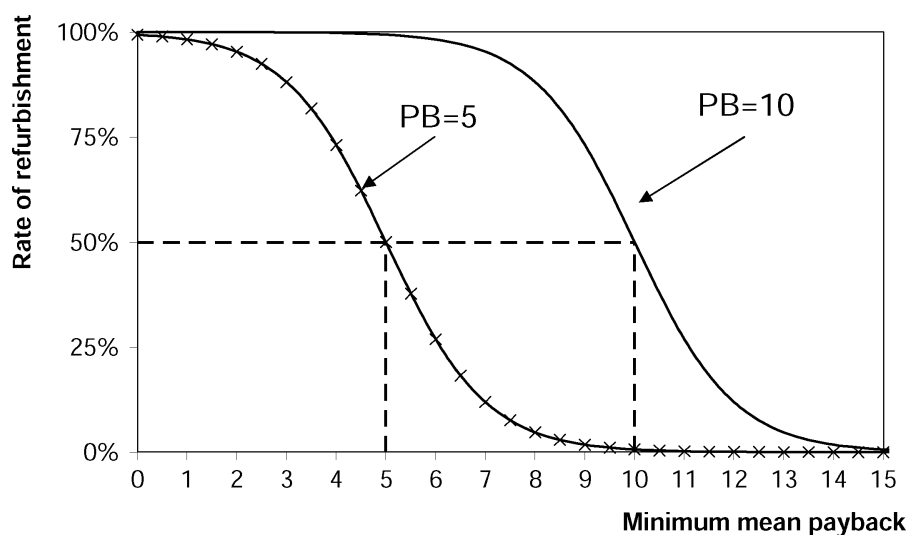

Fig. 4. Sample payback acceptance curve.

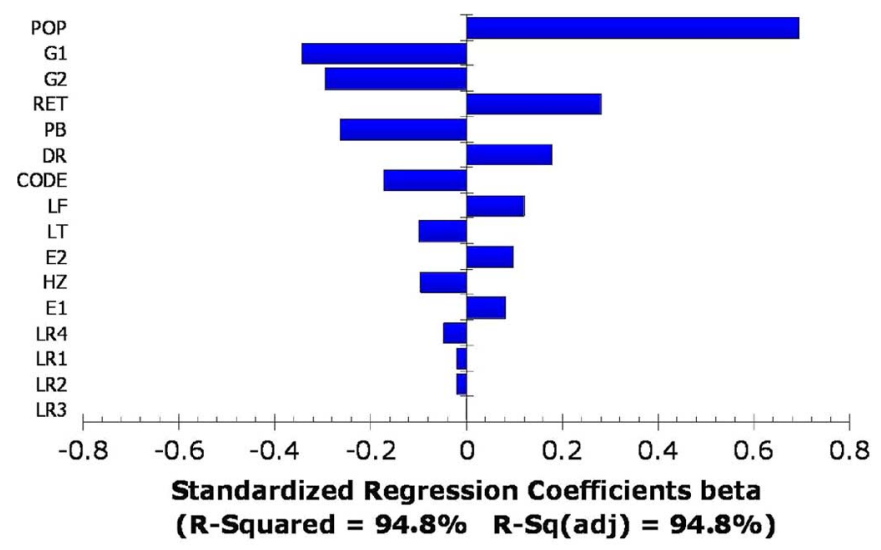

Fig. 5. Sensitivity of the system variables to the 2050 emissions.

influences the payback time of the respective refurbishment measures, i.e.

$$
P B(i, \mathrm{st})=\frac{\Delta I(i, \mathrm{st})-\mathrm{SUB} \cdot \Delta \mathrm{CO}_{2}(i, \mathrm{st})}{\Delta E(i, \mathrm{st}) \cdot P_{e}}
$$

where $P B(i, \mathrm{st})=$ simple payback time of refurbishment standard st for dwelling component $i, \mathrm{SUB}=$ subsidies, $\Delta \mathrm{CO}_{2}=$ $\mathrm{CO}_{2}$ emissions avoided over the lifetime of the insulation standard st, $\Delta I=$ additional investment costs related to the refurbishment standard st, $\Delta E=$ resulting energy savings, and $\mathrm{P}_{\mathrm{e}}=$ energy price. From (9), increasing the subsidy decreases the payback time, which in turn leads to higher investment and hence to less $\mathrm{CO}_{2}$.

Furthermore, different building codes (CODE) are imposed on the construction of new homes. Tightening of building codes in the period 1996-2006 caused a reduction of energy use for space heating and hot water production for new homes of about $5 \%$ per year on average [27]. We assume a range of $2.5 \%$ to $5 \%$ in average annual reductions achieved in new dwellings as result of different scenarios related to future building codes. Lastly, occupation density is analyzed using the lifestyle variable household average size $(H Z)$ and uncertainty about the future activity of the sector as expressed using a population growth multiplier $(P O P)$.

Fig. 5 shows the results of the sensitivity analysis for the emissions levels in 2050, obtained from 50000 model runs with subsidies set to $20 € \mathrm{CO}_{2}$. The tornado diagram illustrates the im-

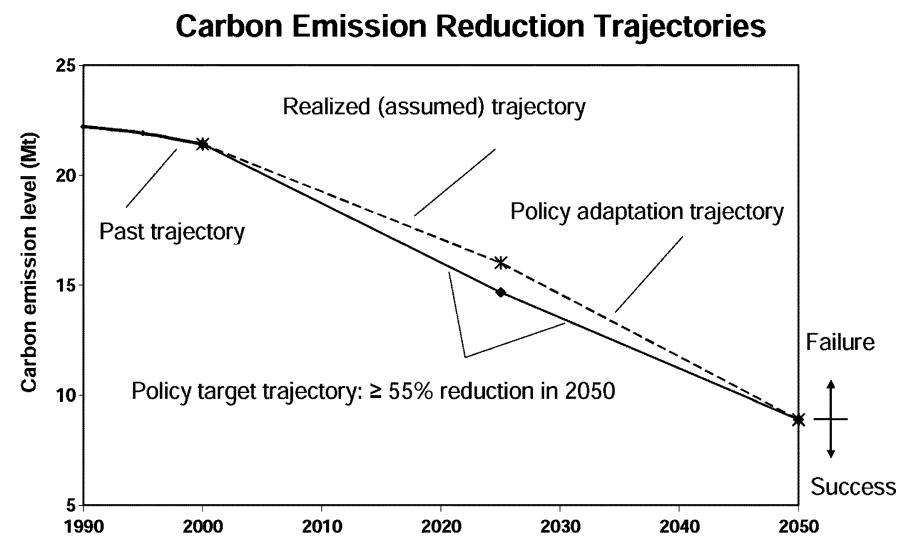

Fig. 6. Assumed trajectories of carbon emissions reductions.

pact of the respective variables on the outcome of interest. The diagram shows the effect size and direction of the individual input variables given the model results based on standardized regression coefficients. Population dynamics $(P O P)$ have the greatest impact on the model outcomes, followed by gas prices ( $G 1$ and $G 2$ ), the demolition of dwellings (RET) and the payback acceptance for refurbishment measures $(P B)$. While, for example, an increase in the standard deviation of population growth has a positive effect on the model results, i.e., emissions will increase, an increase in the standard deviation of gas prices or payback acceptance leads to emission reductions.

\section{B. Computational Experiments and Sampling}

Computational experiments were carried out across the uncertainty space defined in the previous section. We used Computer Assisted Reasoning System (CARS) Software to perform our experiments [28]. The software treats a model (in this case a spreadsheet) as a black box, and maps model inputs to outputs, creating a database of model runs. A set of inputs is created by Latin-Hypercube sampling (LHS). LHS is most beneficial for long-running models [29], [30]. LHS forces the specified sample size, $n$, to cover the whole experimental space. Sampling without replacement is performed so that with $n$ samples every segment is sampled once. Compared to random sampling, LHS produces a sample that is random but that is relatively uniformly distributed over each dimension. We take 50000 samples of data sets across the uncertainty space over the 50-year period. The choice of this number of samples is explained in the Appendix.

\section{AdAPtive Policy Design}

\section{A. Trajectories of Carbon Emission Reduction}

Based on the policy target information in Section III, we establish several trajectories for carbon emissions reductions (see Fig. 6). As a policy target, the carbon emission level should be reduced to around 15 Mton in 2025, which corresponds to a reduction of about $30 \%$ compared to 1990 levels. Furthermore, the emissions should be brought down to 10 Mton in 2050 (i.e., a 55\% reduction from the 1990 level). A policy can be considered successful when the resulting emission level in 2050 is less than or equal to 10 Mton. 


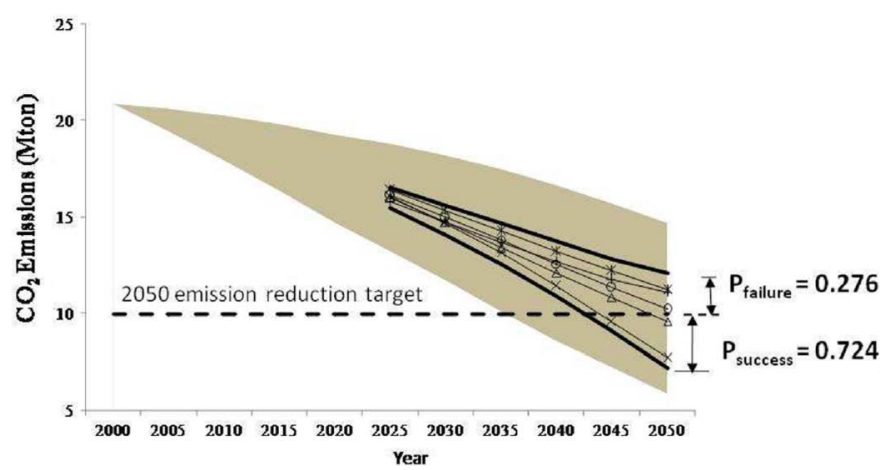

Fig. 7. Probability of success and failure of the $50 €$ subsidy.

Suppose, for example, that a subsidy of $20 €$ per ton $\mathrm{CO}_{2}$ avoided has been implemented for the 2000-2025 period. The circumstances turn out to be such that the target of 15 Mton in 2025 cannot be met. Instead, the trajectory goes off-target at around 16 Mton. Such a path, which coincides with a long-term scenario study recently carried out in the Netherlands [31], and depicted as the "realized (assumed) trajectory" in Fig. 6. The question under such circumstances is, having missed the target of 2025, what conditions are required to bring the emissions levels back in line to hit the target for 2050 (i.e., the "policy adaptation trajectory" in Fig. 6).

\section{B. Analysis of the Impact of Policy Instruments}

Under this condition, relevant decision-makers across SoS levels are faced with two broad types of factors: those over which they have direct influence and the rest. Decision-makers at delta level (e.g., ministry of economic affairs), for instance, have little influence on demographic factors such as population growth and household size, and therefore would like to be protected against variability involving these factors. Given such uncertainty, it is desirable to pursue a robust policy [32]. One means to achieve this robustness is to do parametric analysis for factors under the influence of DM and probabilistic analysis for factors beyond the influence of decision-makers [33].

As part of a parametric analysis, three cases of subsidy arrangements are tested. The first arrangement is a subsidy of 20 €per ton $\mathrm{CO}_{2}$ maintained for the period 2025-2050, whereas the second and third are a subsidy of 50 Gand $70 €$ eper ton $\mathrm{CO}_{2}$, respectively (i.e., SUB2 $=20 € 50 €$ and $70 €$ ). These three subsidy levels represent one instrument that decision-makers at delta level can exercise to influence the performance of the SoS.

To represent the actual emissions level of 16 Mton in 2025, we take a range of 15.5 to 16.5 Mton in order to collect sufficient data sets from the database of model runs, resulting in 18596 data sets. One data set features an LHS sample of the uncertainty space in Table II with associated emission level trajectories. The data sets that support either policy success or failure are counted to establish the probability of success and failure. This procedure is similar to that used to establish the strength of a decision rule by counting the number of data sets supporting a particular rule [34].

Fig. 7 shows the result for a 50 esubsidy level. Due to path dependency, the resulting emission trajectories from 2025 to 2050
TABLE IV

Subsidy INFLUENCE ON OVERALl SySTEM PERFormanCE

\begin{tabular}{lccc}
\hline Subsidy level (2025-2050) & $20 €$ & $50 €$ & $70 €$ \\
\hline $\mathrm{P}_{\text {success }}$ & 0.644 & 0.724 & 0.748 \\
\hline $\mathrm{P}_{\text {failure }}$ & 0.356 & 0.276 & 0.262 \\
\hline
\end{tabular}

are bounded (some of the sampled trajectory regions are highlighted). The shaded area bounds all trajectories from 2000 to 2050. $72.4 \%$ of the 18596 trajectories end up at or below the 2050 target of 10 Mton, yielding a probability of success or failure of 0.724 and 0.276 , respectively.

Complete performance data for the three subsidies is given in Table IV. According to the model, increasing the subsidy from 20 to 50 to 70 will increase the probability of success from 0.644 to 0.724 to 0.748 . This result shows the diminishing returns of the system in response to increasing subsidy level.

\section{CART Analysis to Inform Policy Adaptation}

To inform policy adaptation, the pattern of system behavior is derived using a pattern recognition process called Classification and Regression Tree (CART) analysis [35]. We apply a nonparametric classification algorithm, which consists of a sequence of binary split mechanism, to the database of model runs. As a result, we obtain a classification tree of input variables with end nodes of model output categories. For the input variables, each level of split determines the importance of the variables in the classification process: the higher the hierarchy of the split, the more important the variable is in influencing the output variable. In this way, CART can be considered a global sensitivity analysis technique.

Fig. 8 shows the CART result for the 50 Esubsidy policy with two end node categories (category $\mathrm{S}=$ policy success and category $\mathrm{F}=$ policy failure). The way to "read" a CART decision rule is to follow the inequality condition given at a certain CART branch (e.g., $L T<6.05$ ). If the condition is satisfied, the rule proceeds to the left of the split (otherwise to the right of the split) and so on until an end node is reached.

From the resulting CART, five main factors appear to exert the greatest impact on system performance. In decreasing order of importance these are: $L T, G 2, P O P, C O D E$, and E2. A policy success mode with the highest likelihood $(\mathrm{p}=0.55$, Branch 1$)$ involves a combination of a set of high range $L T$ values and high $G 2$. This combination is a favorable one. High $L T$ values represent a large market share for cost-effective heating technologies and high $G 2$ values incentivize homes to invest in more energy-efficient heating technologies by yielding higher cost savings and a faster payback period. On the other hand, the opposite scenario (i.e., low $L T$ and low $G 2$ ) with high population growth (unfavorable combination) will lead to a failure mode with the highest likelihood ( $p=0.053$, Branch 2).

The above results highlight a useful CART feature. When a split takes place at one level that defines $\mathrm{S}$ and $\mathrm{F}$, a higher value makes the variable at a lower level irrelevant. So in this case $G 2$ is medium to high value (i.e., $G 2>3.15 \%$ regardless of the realization values of the rest of the variables. CART not only informs which variables are important but also when they matters.

Also, CART highlights the boundary line between failure and success. A metaphor of "land mines" or "fault lines" is often 


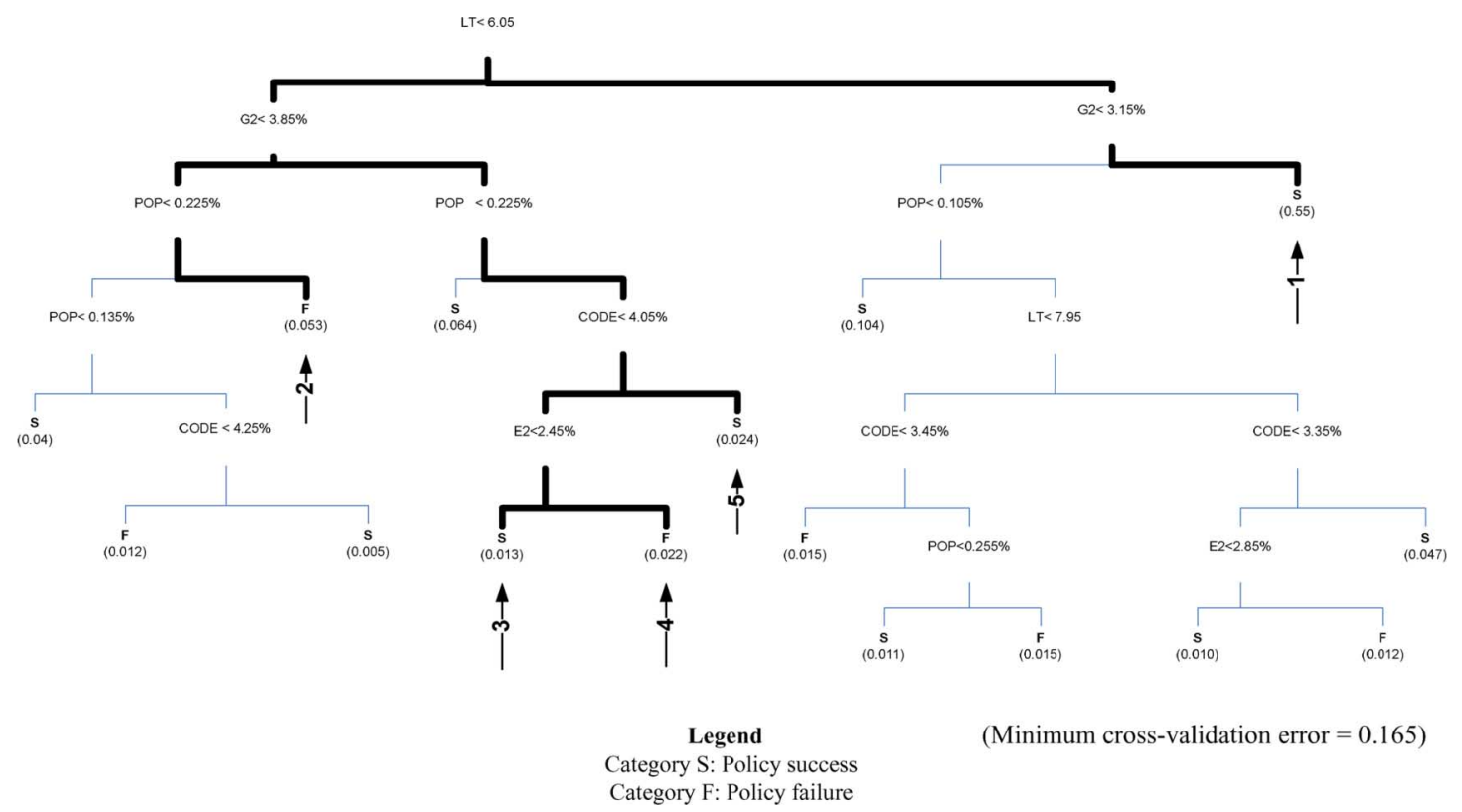

Fig. 8. CART result as a basis for policy adaptation.

used to describe these kind of combinations [36]. By following the decision rules suggested by Branch 3 and Branch 4, we can establish that, ceteris paribus, whether the policy target is achieved is determined by whether the E2 is in the low range value (success) or medium and high range value (failure). In this situation, once the variable is headed towards the failure mode range, one needs to climb the CART hierarchy in order to guard against a failure mode. If $\mathrm{E} 2$ rises above $2.45 \%$, one needs to increase the CODE variable to more than $4.05 \%$ to avoid failure and achieve policy success (Branch 5).

\section{Tradeoffs Among SoS Actors}

In addition to general insights regarding overall system behavior, it may be useful to look at specific trade-offs that can be made between SoS actors. Within an SoS, multiple solutions (toward achieving a policy target) can be obtained from multiple sets of variable values, such that each of the variables is under the control of different actors. To illustrate, we take three data sets that belong to Branch1 and plot them as a spider chart (see Fig. 9). The trade-offs among system variables in affecting the carbon emissions level are informed by the sensitivity analysis depicted in Fig. 5. A system variable that affects emissions in a positive direction can be compensated to a certain extent by a realization of another variable with a negative direction effect.

The chart in Fig. 9 clearly shows, for example, that in Tradeoff1, given a high value of building refurbishment $L F$, value (under the control of housing developers) is compensated for by the high growth of gas prices, $G 2$ (under the control of utility companies). However both can withstand a high payback requirement (under the control of housing developers). In contrast, Trade-off 3 requires a high value for building codes (under the control of ministry of housing) and technology diffusion $L T$ (under the control of housing owner) to compensate for a low value of $G 2$. This combination, in effect, can withstand a high value of the discount rate $D R$ (under the control of the owner).

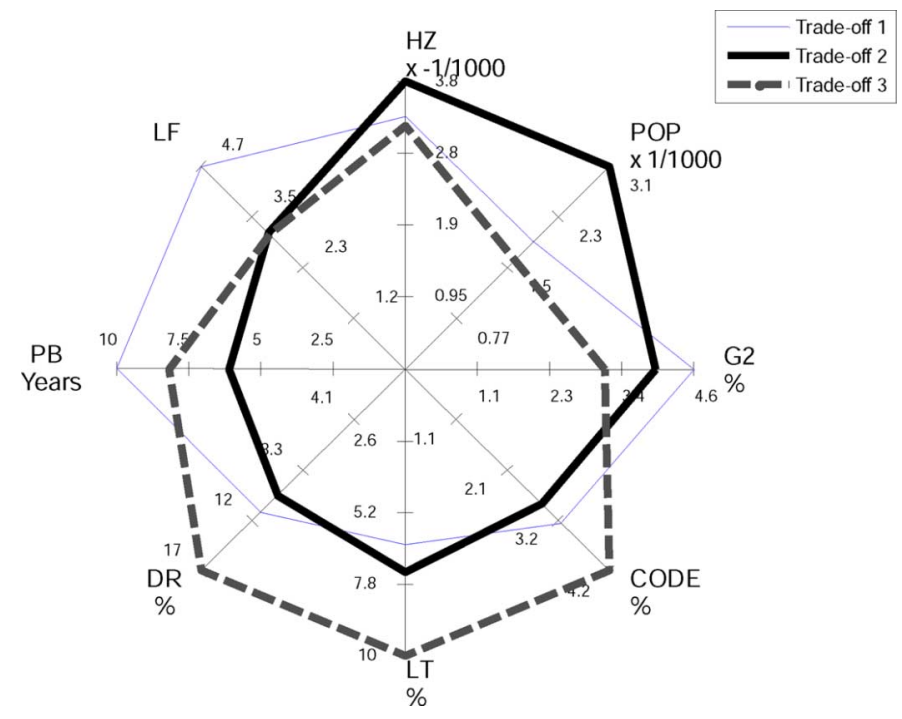

Fig. 9. Some possible tradeoffs among SoS actors.

\section{E. Implications for Adaptive Policy Design}

The implication for adaptive policy design is that decisionmakers should focus on and choose a policy set based on the probability of success as well as the chance that it can influence relevant system variables. The resulting CART in the form of 'if-then' decision rules becomes the basis to inform adaptive policy design.

There exist certain value combinations of the system variables that are most likely to achieve the policy target. Our analysis reveals the two most influential variables: gas price and technology diffusion parameter. As long as the gas price is high and provided that cost-effective heating technologies gain a solid market share, the policy target can be achieved. Under this condition, achieving the policy target is insensitive to realizing other variables. Decision-makers can influence 
the price of gas, by taxation for instance, and can influence technology diffusion by offering subsidies.

Besides the probability of success, there is an issue of feasibility. Using taxation to influence the price of gas might be less feasible (due to political concerns) than influencing investment in better technology by granting a subsidy. So, from a SoS perspective, besides the price of gas, $G 2$ and technology diffusion at the $\beta$ level, other policy options should also be considered. We especially recommend influencing the demolition rate, RET ( $\gamma$ level). Alternatively, one could influence the standard of a building's energy performance, $C O D E$ ( $\delta$ level). Other policy alternatives might include an awareness campaign to break down the barriers to technology investment represented by the high discount rate $D R$ ( $\beta$ level). Some reductions in rental rates might help so that housing developers can pursue a more aggressive refurbishment plan, $L F$ ( $\gamma$ level). Our SoS perspective provides a conceptual framework to structure the complexity of policymaking, taking into account the interactions and possible tradeoffs among the SoS levels.

The insights into the trade-offs among actors can inform decision-makers about the compromises they can make to achieve their policy goals. Since the policy target can be reached by shifting the burdens between actors, a kind of burden-sharing scheme based on equity principles can be established (see e.g., [37])

Lastly, often ambitious targets are established without a clear idea of what would be required to achieve them. For instance, some of our findings suggest that for a certain set of future goals, a zero or negative population growth is required to achieve the policy target. When the population actually increases, the target will be out of reach, requiring further changes to system constraints (e.g., higher growth rates for gas price) or additional policies that promote the use of lower- or zero-carbon fuels. The approach we propose can be used to test the achievability of any policy target.

\section{CONCLUDING REMARKS}

In a complex and uncertain world, decision-makers need to know how each policy option will perform given uncertainty. Our approach can help. Our paper analyzes a special case where the intermediate target is missed. In contrast to an optimal approach, we have demonstrated how the adaptive policy approach can be applied under conditions of uncertainty, enabling a policy to be adapted as some of the uncertainties are resolved. Integral to our approach is the exploratory modeling and analysis method which leads to insights that can be used to support the design of an adaptive policy.

Exploratory modeling and the CART method offer insights into the boundaries between policy success and failure. Further analysis reveals the tradeoff among SoS variables and possible pathways for policy adaptation. This high level of policy insight is arguably more useful than a very detailed model at the initial stages of policy analysis [17]. Policy design should focus on factors that decision-makers can feasibly influence with a high probability of success. The System-of-Systems perspective, in this case, provides the problem definition commensurate with the complexities of the issue at hand, allowing us to identify and specify different kinds of systems at various levels.

\section{APPENDIX}

The objective of this section is to explore the appropriate number of samples for computational experiments. We examine the effect of 10000, 50000 and 75000 samples on the performance of CART. The results are listed in Table IV. The measures include: misclassification error rate, no. of terminal nodes, running time, and result bounds.

There are two kinds of misclassification errors. The first is a so-called resubstitution error. This measures how well the resulting tree classifies all the sampled data. However, the resubstitution error is typically lower than the "true error" (namely the error when the tree is used to classify data excluded from sampling). Ideally, the tree should be tested with a completely new data set. However, since we failed to use a second data set, cross validation can be employed, hence the second type of misclassification error [35]. A new data set is created by removing $10 \%$ of the data, constructing a tree using the remaining $90 \%$, and using the resulting tree to classify the missing $10 \%$. This process is repeated by removing each of ten subsets one at a time.

The error rates of the classification tree (CART) against the CART size (i.e., the number of terminal nodes) can be plotted to identify behaviors of interest (see Fig. 10). First, the resubstitution error decreases as the tree gets bigger (i.e., the number of terminal nodes increases). Second, the cross-validation error reveals an optimal size of the classification tree that produces a minimum misclassification error. One can simply choose the tree with the smallest cross-validation error. While this may be satisfactory, one might prefer to use a simpler tree if it is about as good as a more complex tree. So, here we take the simplest tree that is within one standard error of the minimum (i.e., marked as "best choice" in Fig. 10). Beyond this optimal size, the cross-validation error increases as the tree gets bigger. Thus, a large tree may be good at classifying existing data but can be weak at classifying data that is excluded from the sampling. As a result, a smaller tree with the optimum size should be used.

Table V shows that for 10000 samples, the best size of classification tree features 142 terminal nodes. This size corresponds with the minimum misclassification error (i.e., cross-validation) of around $28.1 \%$. This means that for the 10000 samples of data, 2810 data elements are misclassified by the resulting classification tree. The misclassification error figures are $24.4 \%$ and $23.4 \%$ for 50000 and 75000 samples. Thus, the higher the number of samples, the lower the minimum cross-validation error.

A bigger number of samples also increases the size of the "best" classification tree. The best size is the classification tree (a so-called "pruned tree") with 142, 572, and 952 terminal nodes for 10000,50000 , and 75000 samples, respectively.

A higher number of samples produces a lower misclassification error. However, larger numbers of samples result in a bigger 'best' classification tree, which can be less comprehensible than a smaller tree. Furthermore, a larger number of samples also requires more running time. A balance needs to be found in this respect.

The 10000 samples require (on a $3 \mathrm{MHz}$ Pentium 4 processor) about $14100 \mathrm{~s}$ computational time $(3.9 \mathrm{~h})$. The 50000 
TABLE V

Summary of CART PERFoRMance MEASURES

\begin{tabular}{|c|c|c|c|c|c|}
\hline \multirow[t]{2}{*}{$\begin{array}{c}\text { No. } \\
\text { samples }\end{array}$} & \multirow{2}{*}{$\begin{array}{c}\text { Misclassification error } \\
\text { rate }\end{array}$} & \multirow{2}{*}{$\begin{array}{c}\begin{array}{c}\text { No. of terminal } \\
\text { nodes }\end{array} \\
\text { Best choice } \\
\end{array}$} & \multirow{2}{*}{$\begin{array}{l}\text { Running } \\
\text { time } \\
\text { (seconds) }\end{array}$} & \multicolumn{2}{|c|}{$\begin{array}{l}\text { Result bounds (Emission level } \\
2050, \text { Mton) }\end{array}$} \\
\hline & & & & Lower & Upper \\
\hline 10,000 & 0.2806 & 142 & 14,100 & 6.47 & 16.91 \\
\hline 50,000 & 0.2436 & 572 & 77,700 & 6.48 & 16.77 \\
\hline 75,000 & 0.2341 & 952 & 111,300 & 6.41 & 16.81 \\
\hline
\end{tabular}

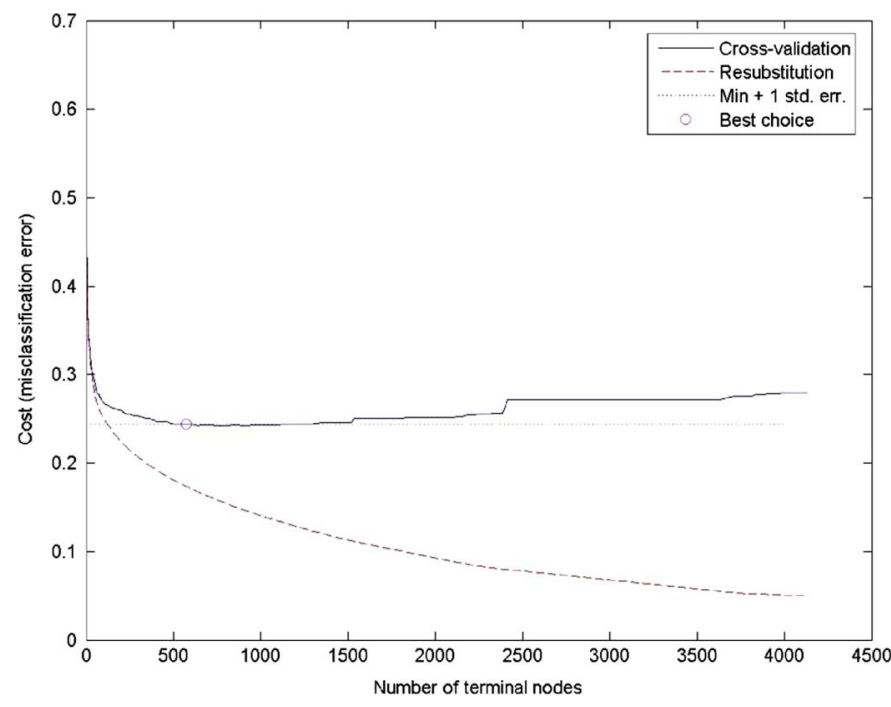

Fig. 10. Cross-validation and resubstitution error versus the number of terminal nodes for 50000 samples.

and 75000 samples require around 5.5 and 7.9 times more computational time respectively than the 10000 samples does.

To assess the result boundaries, we define CART coverage as the range that captures the lower and upper bound of total emission level in 2050 across all three sample sets. Here the focus is to assess whether the different sample numbers avoid the extreme/fringe regions of the outcomes space. At the lower bound, the relative difference between the maximum (6.48 Mton) and minimum value (6.41 Mton) of emissions levels is about $0.9 \%$. Toward the upper bound, the difference is about $0.8 \%$. The differences appear to be not significant given the number of samples. CART coverage alone cannot be used as a determinant of best sample size.

In summary, we conclude that to determine the best sample size for the household heating case, we can safely use only misclassification error and running time. To select a proper number of samples, it is important to choose a balance between benefit and cost. Benefit is defined in terms of a reduction in misclassification errors, whereas cost is defined in terms of increased computational time.

To establish an appropriate number of samples, we normalized each measure [Fig. 11(a)]. On the gain side, we chose the value of 0 for the error rate in the case of 10000 samples and 100 for 75000 samples. We applied the reverse for the cost side. Fig. 11(b) shows the gain-cost ratio for three cases: going from 10000 to 50000 and 75000 , and 50000 to 75000 . We conclude that going from 10000 to 50000 samples produces the highest gain-cost ratio [Fig. 11(b)]. Therefore, assuming that

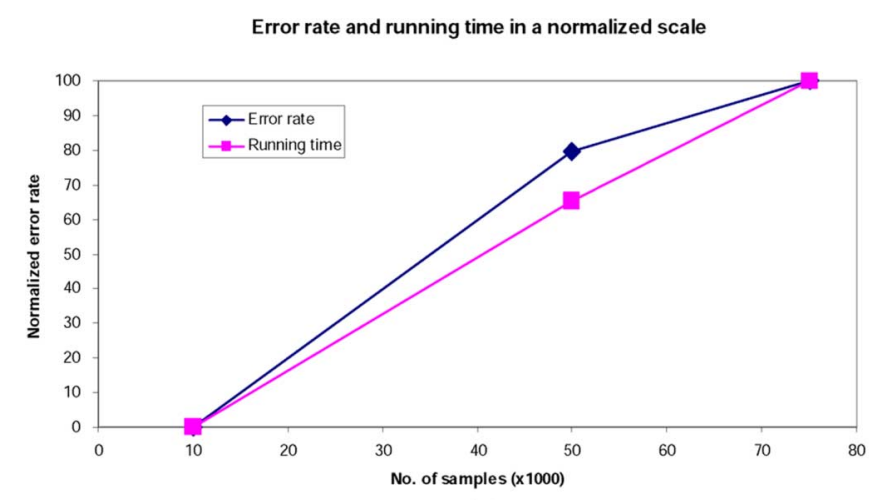

(a)

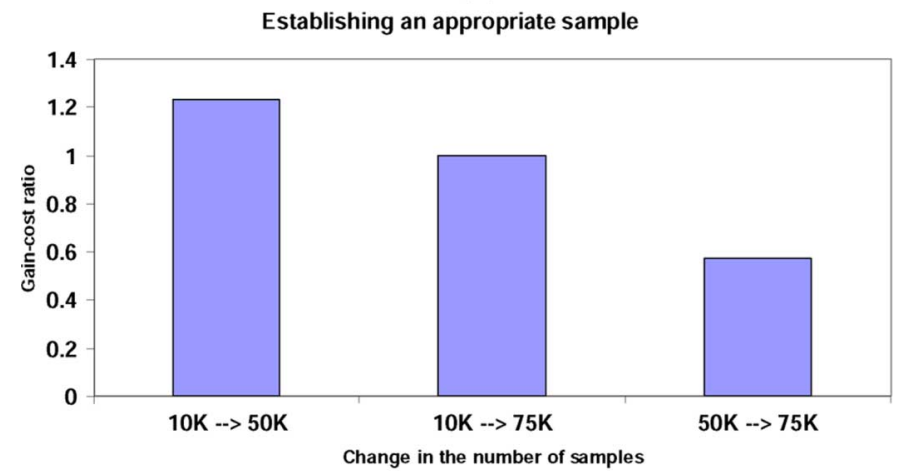

(b)

Fig. 11. Gain-cost ratio for the number of extra samples.

the marginal resources required and the error rate have an equal weight in terms of importance, the 50000 samples appear to be appropriate.

\section{ACKNOWLEDGMENT}

The authors are grateful for the valuable comments of W. Thissen, W. Walker, D. DeLaurentis, and A. Faaij.

\section{REFERENCES}

[1] K. W. Hipel, M. M. Jamshidi, J. M. Tien, and C. C. White, "The future of systems, man, and cybernetics: Application domains and research methods," IEEE Trans. Syst., Man, Cybern. C: Applicat. Rev., vol. 37, pp. 726-743, 2007.

[2] R. J. Lempert, N. Nakicenovic, D. Sarewitz, and M. Schlesinger, "Characterizing climate-change uncertainties for decision-makers: An editorial essay," Climatic Change, vol. 65, pp. 1-9, 2004.

[3] M. G. Morgan and M. Henrion, Uncertainty: A Guide to Dealing with Uncertainty in Quantitative Risk and Policy Analysis. Cambridge, U.K.: Cambridge Univ. Press, 1992.

[4] D. DeLaurentis and R. K. C. Callaway, "A system-of-systems perspective for public policy decisions," Rev. Policy Res., vol. 21, pp. 829-837, 2004. 
[5] W. E. Walker, "Policy analysis: A systematic approach to supporting policymaking in the public sector," J. Multi-Criteria Decis. Anal., vol. 9, pp. 11-27, 2000.

[6] R. J. Lempert, S. W. Popper, and S. C. Bankes, Shaping the Next One Hundred Years: New Methods for Quantitative, Long-Term Policy Analysis 2003, RAND, Santa Monica, CA, MR-1626-RPC.

[7] J.-H. Lewe, D. A. DeLaurentis, D. N. Mavris, and D. P. Scharage, "Entity-centric abstraction and modeling framework for transportation architectures," J. Air Transport., vol. 11, 2006.

[8] W. E. Walker, S. A. Rahman, and J. Cave, "Adaptive policies, policy analysis, and policy-making," Eur. J. Oper. Res., vol. 128, pp. 282-289, 2001.

[9] R. J. Lempert, M. E. Schlesinger, and S. C. Bankes, "When we don't know the costs or the benefits: Adaptive strategies for abating climate change," Clim. Change, vol. 33, pp. 235-274, 1996.

[10] S. C. Bankes, "Exploratory modeling for policy analysis," Oper. Res., vol. 41, pp. 435-449, 1993.

[11] P. K. Davis, P. K. Davis, Ed., "Planning for adaptiveness," in New Challenges for Defense Planning: Rethinking How Much is Enough RAND. Santa Monica, CA, 1993, MR-400-RC.

[12] Now for Later; Energy Report 2005 Ministry of Economic Affairs. The Hague, The Netherlands, 2005.

[13] K. K. Goldewijk, J. G. J. Olivier, J. A. H. W. Peters, P. W. H. G. Coenen, and H. H. J. Vreuls, Greenhouse Gas Emissions in the Netherlands 1990-2003 National Inventory Report Netherlands Environmental Assessment Agency (MNP). Bilthoven, The Netherlands, 2005.

[14] P. G. Boonekamp, "Improved Methods to Evaluate Realized Energy Savings," Doctoral Dissertation, Utrecht University, Utrecht, The Netherlands, 2005.

[15] C. Petersdorff, T. Boermans, and J. Harnisch, "Mitigation of $\mathrm{CO}_{2}$ emissions from the EU- 15 building stock: Beyond the eu directive on the energy performance of buildings," Environ. Sci. and Pollution Res., vol. 13 , pp. 350-358, 2006.

[16] D. J. Treffers, A. P. C. Faaij, J. Spakman, and A. Seebregts, "Exploring the possibilities for setting up sustainable energy systems for the long term: Two visions for the dutch energy system in 2050," Energy Policy, vol. 33, pp. 1723-1743, 2005.

[17] D. B. Agusdinata and D. DeLaurentis, "Specification of system-of-systems for policymaking in the energy sector," Integr. Assess. J., vol. 8, pp. 1-24, 2008.

[18] L. Dittmar, A. P. C. Faaij, and W. C. Turkenburg, DREM: The Dutch Residential Energy Model Utrecht University. Utrecht, The Netherlands, 2007.

[19] C.-O. Wene, Experience Curves for Energy Technology Policy Org. Economic Co-operation and Development Int. Energy Agency. Paris, France, 2000.

[20] Perspectives on Experience Boston Consulting Group (BCG). Boston, MA, 1972.

[21] D. W. Boyd, R. L. Phillips, and S. G. Regulinski, "A model of technology selection by cost minimizing producers," Manag. Sci., vol. 28, pp. 418-424, 1982.

[22] J. F. Clarke and J. A. Edmonds, "Modeling energy technologies in a competitive market," Energy Econom., vol. 15, no. 2, p. 123, 1993.

[23] A. H. Sanstad, C. Blumstein, and S. E. Stoft, "How high are option values in energy-efficiency investments," Energy Policy, vol. 23, pp. 739-743, 1995.

[24] I. M. Johnstone, "Energy and mass flows of housing: A model and example," Build. Environ., vol. 36, no. 1, pp. 27-41, 2001.

[25] M. Elsinga and C. Lamain, Demolition and Survival Function of Housing Buildings (in Dutch) OTB Research Institute for Housing, Urban and Mobility Studies. Delft, The Netherlands, 2004, (unpublished).

[26] P. C. F. Bekker, A Lifetime Distribution Model of Depreciable and Reproducible Capital Assets VU Univ. Press. Amsterdam, The Netherlands, 1991.
[27] K. Blok, "Improving energy efficiency by five percent and more per year?," J. Ind. Ecol., vol. 8, pp. 87-99, 2004

[28] S. Bankes, R. J. Lempert, and S. Popper, "Making computational social science effective: Epistemology, methodology, and technology," Soc. Sci. Comput. Rev., vol. 20, pp. 377-388, 2002.

[29] M. D. McKay, R. J. Beckman, and W. J. Conover, "Comparison of 3 methods for selecting values of input variables in the analysis of output from a computer code," Technometrics, vol. 21, pp. 239-245, 1979.

[30] J. C. Helton and F. J. Davis, "Latin hypercube sampling and the propagation of uncertainty in analyses of complex systems," Reliab. Eng. Syst. Safety, vol. 81, pp. 23-69, Jul. 2003.

[31] L. H. J. M. Janssen, V. R. Okker, and J. Schuur, Welfare, Prosperity and Quality of the Living Environment: A Scenario Study for the Netherlands in 2040 (in Dutch). Den Haag, The Netherlands, 2006, Centraal Planbureau, Natuurplanbureau, Ruimtelijk Planbureau.

[32] R. J. Lempert, D. G. Groves, S. W. Popper, and S. C. Bankes, "A general, analytic method for generating robust strategies and narrative scenarios," Manag. Sci., vol. 52, pp. 514-528, 2006.

[33] M. Morgan and D. Keith, "Improving the way we think about projecting future energy use and emissions of carbon dioxide," Clim. Change, vol. 90, pp. 189-215, 2008.

[34] Z. Pawlak, "Rough set approach to knowledge-based decision support," Eur. J. Oper. Res., vol. 99, pp. 48-57, 1997.

[35] L. Breiman, J. H. Friedman, C. J. Olshen, and C. J. Stone, Classification and Regression Trees. Monterey, CA: Wadsworth, 1984.

[36] R. Lempert, S. W. Popper, and S. C. Bankes, Shaping the Next One Hundred Years, New Methods for Quantitative Long-Term Policy Analysis. Santa Monica, CA: The RAND Pardee Centre, 2003, MR-1626RPC.

[37] K. Vaillancourt and J. P. Waaub, "Equity in international greenhouse gases abatement scenarios: A multi-criteria approach," Eur. J. Oper. Res., vol. 153, pp. 489-505, 2004.

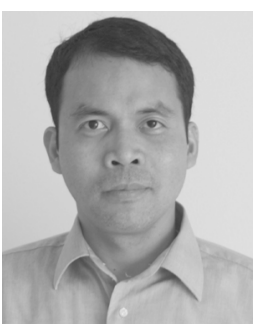

Datu Buyung Agusdinata received the B.S. degree in 1991 from Bandung Institute of Technology, Bandung, Indonesia, the M.S. degree in aerospace engineering in 1999 and the Ph.D. degree in policy analysis in 2008, both from Delft University of Technology, Delft, The Netherlands.

He is currently a Postdoctoral Fellow at the School of Aeronautics and Astronautics, Purdue University, West Lafayette, IN. He was previously a Junior Lecturer in the Faculty of Aerospace Engineering, Delft University of Technology. He has also worked as an analyst at Aircraft Design and System Engineering (ADSE) Company in The Netherlands.

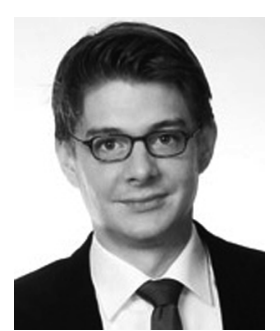

Lars Dittmar received the Diploma in energy and environmental management in 2005 from the University of Flensburg, Flensburg, Germany.

From 2005 to 2007, he was a Ph.D. Researcher at the Copernicus Institute for Sustainable Development and Innovation, Utrecht University, Utrecht, The Netherlands. He is currently a Research Associate at the Department of Energy Systems, Berlin Institute of Technology, Berlin, Germany. 